\title{
Buena gobernanza de los bienes comunes de Rapa Nui: presente y pasado
}

\section{Good governance of the commons of Rapa Nui: present and past}

\author{
Pamela A. Mischen', Carl P. Lipo² y Terry L. Hunt ${ }^{3}$
}

\begin{abstract}
RESUMEN
La sustentabilidad de las comunidades en Rapa Nui (Isla de Pascua, Chile) requiere de una buena gobernanza de los recursos compartidos y comunes. Las estructuras de gobierno deben equilibrar los intereses individuales con las necesidades comunes de la comunidad, ya sea en la gestión de tierras comunales necesarias para el cultivo, el agua subterránea, las piedras para herramientas, los caladeros, el patrimonio cultural o el turismo. Gran parte de la historia reciente de la isla ha estado dominada por estructuras de gobierno impuestas por las autoridades chilenas. Sin embargo, gran parte de su patrimonio cultural se transfirió recientemente a la gobernanza local nativa. Aunque esto implica desafíos debido a la complejidad del paisaje contemporáneo, es un gran avance hacia la rendición de cuentas, la inclusión y las necesidades locales. Finalmente, se compara con la gobernanza previa al contacto europeo, y sostenemos que se mantuvieron muchos retos y soluciones, aunque con distinciones importantes.
\end{abstract}

Palabras clave:

ABSTRACT

Sustainable communities on Rapa Nui (Easter Island, Chile) - whether in the past or present- require good governance of shared and common pool resources. Whether managing communal land needed for cultivation, ground water, stones for tools, fishing grounds, cultural heritage, or tourism, governance structures must balance individual interests with the common needs of the community. Much of the recent history of the island has been dominated by government structures that were imposed by Chilean authorities. Recently, however, much of the island's cultural heritage has been turned over to local native governance. This shift has challenges due to the complex contemporary landscape but is a significant step forward toward addressing accountability, inclusivity, and local needs. Looking at the pre-European contact governance of the island, we argue that many of the same challenges and solutions were adopted with some important distinctions.

Keywords:

Department of Public Administration, Binghamton University, Binghamton, NY 13902; pmischen@binghamton.edu Department of Anthropology, Binghamton University, Binghamton, NY 13902; clipo@binghamton.edu 
Durante más de 800 años, los habitantes de una isla remota y diminuta en el Océano Pacífico sudoriental ha estado enfrentando cuestiones complejas pero fundamentales de gobernanza. La isla de Rapa Nui (Isla de Pascua, Chile) tiene sólo 161 km2 (Figura N 1) y fue colonizada originalmente por polinesios que llegaron en canoas a vela en el siglo XIII d.C. (Hunt \& Lipo, 2006). Durante más de 500 años, los antiguos isleños transformaron la ecología de la isla como efecto de la introducción de ratas (Hunt \& Lipo, 2011), a través de la tala de bosques (Mann, et al. 2003) y mediante la creación de vastos huertos líticos para la producción de alimentos (Wozniak, 1999). También construyeron cientos de estatuas de piedra de varias toneladas (moai), las transportaron a distintas partes de la isla a través del terreno volcánico y las colocaron encima de enormes plataformas de piedra construidas por ellos (ahu) (Lipo, Hunt y Rapu Haoa 2013). Estas representan algunas de las mayores inversiones per cápita en arquitectura monumental conocidas en todo el mundo. En 1722, la isla fue visitada por europeos por primera vez. La historia posterior al contacto de la isla incluye numerosas expediciones europeas, así como oleadas de enfermedades introducidas y redadas devastadoras en las que los isleños fueron expulsados por la fuerza para ser esclavizados (Fischer, 2005). Para 1877, sólo quedaban 111 isleños nativos. En 1888, la isla fue anexada por Chile y arrendada como un rancho de ovejas, un uso que resultó en 60.000 ovejas en la isla, trabajos forzados y enormes daños ecológicos.

La población residente actual de la isla es de aproximadamente 7.750 personas, según datos de 2017. Después de más de 130 años bajo el gobierno de Chile - ubicado a más de $3.600 \mathrm{~km}$ de distancia en mar abierto (figura 1) - , los resilientes isleños trabajan para establecer un sistema de gobernanza que permita gestionar equitativamente los recursos culturales y naturales de la isla, a la vez que se ocupan de los conjuntos de autoridad que se superponen y que provienen de los grupos familiares, de una serie de 10 clanes (mata), de funcionarios de gobierno de las ciudades elegidos por los residentes, de un gobernador provincial nombrado por el Presidente de Chile y de numerosos organismos chilenos a nivel provincial y nacional. En los últimos decenios los problemas de la estructura colonial general de gobernanza han ido en aumento en la medida que los isleños fueron adquiriendo una mayor participación. Así, lograron el ejercicio del derecho de voto en el decenio de 1960 (Tector, 2014), la celebración de referendos para la descolonización en el decenio de 1980 (Delaune, 2012), el nombramiento de su primer gobernador nativo en 1984, su condición de territorio especial en 2007, y demandas por una plena autonomía en las manifestaciones y los conflictos abiertos en el período 2010-2012 (COHA, 2011; Delaune, 2012). El paso más reciente hacia la reforma de la gobernanza de la isla ha sido el establecimiento de la Comunidad Indígena Polinésica Ma'u Henua (en adelante, Ma’u Henua), una organización indígena rapanui que recientemente ha asumido la administración del Parque Nacional que conforma gran parte de la isla, antes administrado por la Corporación Nacional Forestal de Chile (CONAF).

La población actual de la isla no está distribuida uniformemente (figura 2). Más del $94 \%$ de los residentes viven en la ciudad de Hanga Roa, en el extremo oriental de la isla (Instituto Nacional de Estadísticas, 2017). Históricamente, la gran parte del resto de la isla se gestionaba como parque, aunque las transferencias de tierras en los últimos 20 años han llevado a un aumento de la propiedad privada por parte de la población rapanui en muchas de las zonas interiores de la isla. Si bien el acceso está cambiando debido a la privatización, gran parte de la isla ubicada fuera del parque, sigue siendo utilizada como lugar para visitas turísticas y tierras abiertas para el pastoreo común de caballos y ganado, así como para el cultivo dentro de algunos de los sitios arqueológicos (por ejemplo, plátanos y taros cultivados en jardines amurallados conocidos como manavai). 
Figura $\mathrm{N}^{\circ} 1$

La ubicación de Rapa Nui en el rincón más oriental de la Polinesia.

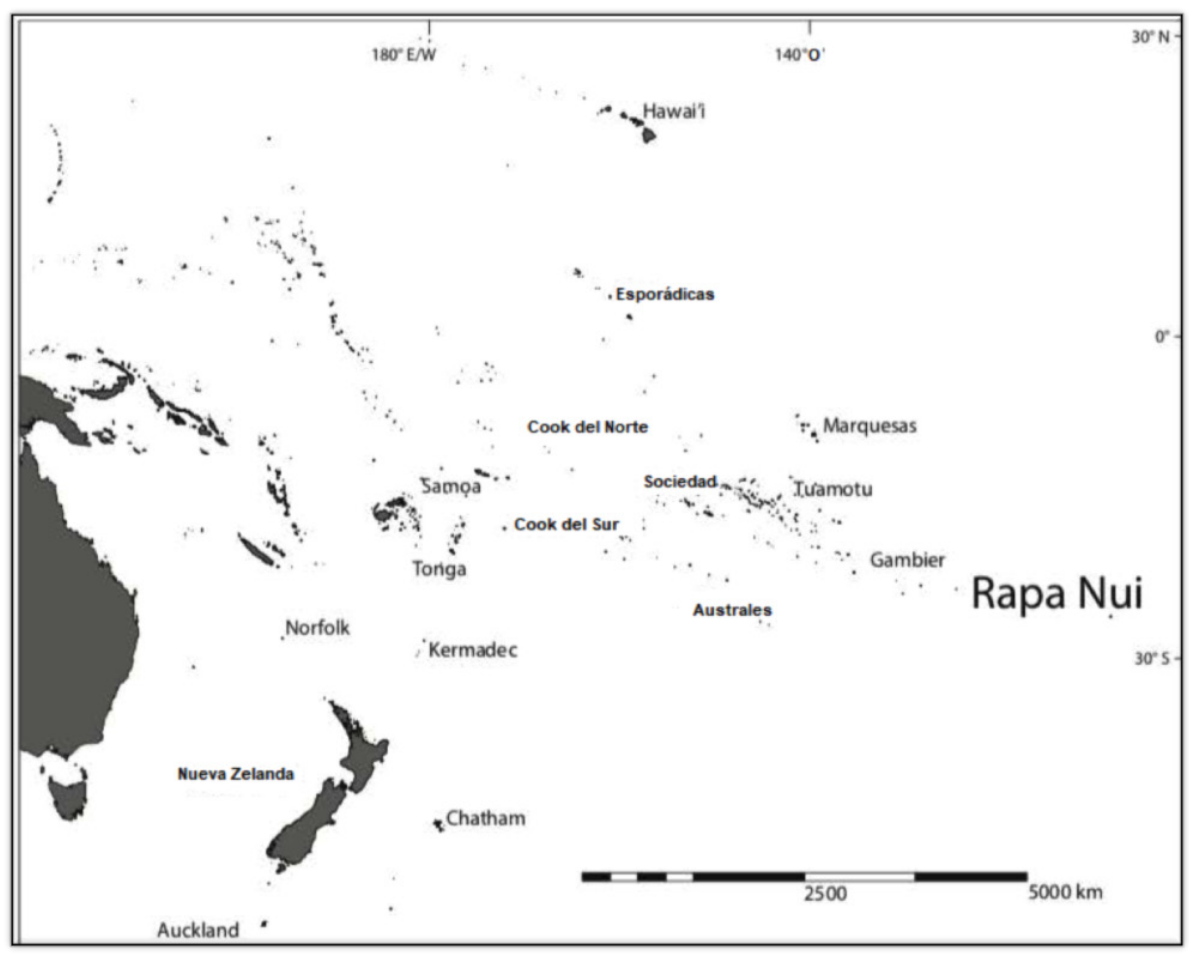

Elaboración propia

Figura $\mathrm{N}^{\circ} 2$

Rapa Nui

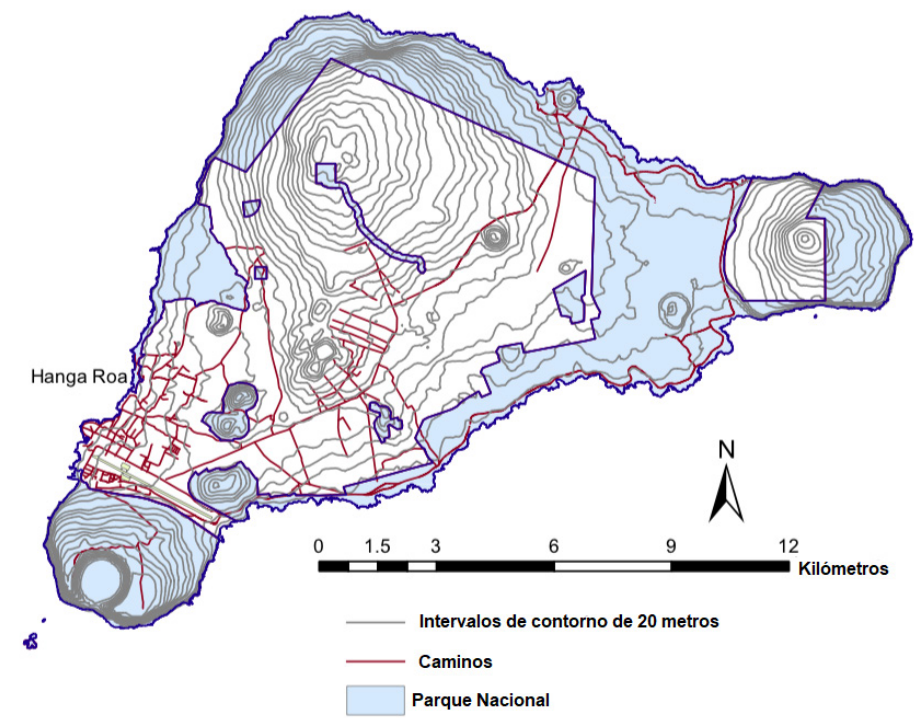

Elaboración propia 
En este artículo, comparamos la gobernanza preeuropea del contacto y una propuesta actual para la gobernanza indígena de Rapa Nui a través del uso de tres prismas: la gobernanza buena/ pública, la gobernanza de los bienes comunes y un movimiento moderno de gobernanza basado en principios indígenas, específicamente el llamado "Buen Vivir". Después de presentar algunos antecedentes sobre cada uno de estos enfoques de gobernanza, revisamos lo que se sabe sobre la gobernanza en tiempos pre-contacto de Rapa Nui con base en la evidencia arqueológica y presentamos una propuesta actual para la transición de la gestión del Parque Nacional Rapa Nui desde el control chileno al indígena bajo el control de Máu Henua. Al realizar un análisis de contenido de esta propuesta, encontramos que los autores apelan a los conceptos de gobernanza buena / pública, gobernanza de los bienes comunes y Buen Vivir. Basándonos en Lipo, Mischen y Hunt (de próxima aparición), afirmamos que las prácticas de gobernanza en la prehistoria condujeron a una gestión de recursos sostenible en Rapa Nui. Sin embargo, el uso moderno de los recursos y las interconexiones globales pueden presentar desafíos a las prácticas de gobernanza tradicionales y pueden requerir el uso de modelos de gobernanza occidentales.

\section{La buena gobernanza pública de los bienes comunes}

El concepto de gobernanza se ha convertido en un objetivo primordial para las comunidades y los países desarrollados y en desarrollo por igual. Aunque el término gobernanza ganó popularidad en las décadas de 1980 y 1990 como parte de las reformas del sector público, y se ha utilizado para transferir las mejores prácticas occidentales a estados no occidentales, se puede argumentar que la gobernanza como práctica ha tenido lugar a lo largo de la historia de la humanidad (Weiss, 2000). Con el fin de cubrir casos contemporáneos, históricos y de gobierno que son anteriores a la documentación escrita, definimos gobernanza como la regla culturalmente heredada para conductas individuales y grupales que sirven para beneficiar a la unidad de organización a nivel de grupo (Lipo, Mischen y Hunt, de próxima aparición).

El concepto de „buena gobernanza” ganó importancia en los años noventa en el contexto del desarrollo económico y social (Bevir, 2009) y se ha utilizado para explicar los fracasos de la gobernanza en Estados no occidentales (White, 2007). Contemporáneo al movimiento de la buena gobernanza, pero con un origen diferente, hay un enfoque en la gobernanza en contraposición al gobierno que surgió del reconocimiento cada vez mayor de la importancia de las redes, las asociaciones y los mercados como actores clave en la formación y aplicación de las políticas públicas. Se han debatido los méritos de la formulación participativa de políticas (véase Peters \& Pierre, 1998 y Kim et al. 2005 para ver las perspectivas que compiten entre sí). En América Latina, esta transición permitió tanto un debilitamiento de la capacidad institucional como una oportunidad para que los grupos indígenas entraran en el proceso de gobernanza (Martí i Puig, 2010).

A pesar de sus diferentes orígenes, Bovaird (2005) argumenta que los dos movimientos cristalizaron en una mayor preocupación por la "gobernanza pública". Los elementos de gobernanza a los que se hace referencia comúnmente en estos movimientos son la rendición de cuentas, la transparencia, la participación, el estado de derecho, la eficiencia, las redes y la globalización. Debido a que gran parte de la preocupación por la gobernanza en Rapa Nui se relaciona con el manejo de los recursos naturales de la isla, un tercer movimiento de gobernanza occidental es relevante: la gobernanza de los bienes comunes. Ostrom (1990) sostiene que, para administrar un bien común de manera sostenible, la comunidad debe: 
1. Definir claramente los límites del grupo.

2. Adaptar las reglas que rigen el uso de los bienes comunes a las necesidades y condiciones locales.

3. Garantizar que las personas afectadas por las reglas puedan participar en la modificación de estas.

4. Asegurarse de que las autoridades externas respeten los derechos de los miembros de la comunidad a dictar reglas.

5. Desarrollar un sistema para monitorear el comportamiento de los miembros de la comunidad.

6. Usar sanciones graduales para los infractores de las reglas.

7. Proporcionar medios accesibles y de bajo costo para la resolución de disputas.

8. Asumir la responsabilidad de gobernar el recurso común en niveles anidados desde el nivel más bajo hasta todo el sistema interconectado.

En resumen, los principios de Ostrom para gobernar los bienes comunes tienen mucho en común con la buena gobernanza pública (por ejemplo, la rendición de cuentas, la participación y el estado de derecho). Esta coincidencia es de esperar, ya que los tres tienen sus raíces en una perspectiva neoliberal basada en la economía clásica que asume que el interés propio individual, cuando se le da libre expresión en el mercado y a través de instituciones democráticas, producirá bienestar público (Clark, 1998). Sin embargo, tales enfoques han recibido críticas cuando se utilizan en estados no occidentales y en el Sur Global. Tales críticas han dado lugar a un giro posneoliberal en América Latina que surgió a principios de este milenio. Grugel y Riggirozzi (2012: 3) argumentan, por ejemplo, que esta reacción es "contra lo que se llegó a ver como una excesiva mercantilización a finales del siglo XX y las democracias elitistas y tecnocráticas que acompañaron las reformas de mercado". Los críticos desafían fundamentalmente las ideas occidentales de "desarrollo" (Caria y Domínguez, 2016; Gudynas, 2011; Villalba, 2013). Este giro ha centrado la atención en la incorporación y el avance de los enfoques de gobernanza indígena.

\section{"Buen vivir" y gobernanza indígena}

De particular importancia en este movimiento en América Latina es el Buen Vivir, que se deriva de los valores compartidos entre los grupos indígenas andinos. Gudynas (2011: 443) argumenta que "«Buen Vivir» no debe ser entendido como un retorno a un pasado andino lejano, a tiempos precolombinos. No es un concepto estático, sino una idea que se crea continuamente". Como tal, la expresión del Buen Vivir varía según el país y el contexto. En Bolivia, el enfoque del Buen Vivir es un principio ético, mientras que en Ecuador se expresa como un conjunto plural de derechos (Gudynas, 2011). Mientras algunos ven al Buen Vivir como consistente con las ideas occidentales de desarrollo sostenible (Walsh, 2010), otros lo ven como una plataforma donde se comparten puntos de vista críticos sobre el desarrollo (Caria \& Domínguez, 2015; Gudynas, 2011).

Villalba (2013) argumenta que existen diferencias clave entre las cosmovisiones occidentales de la gobernanza y los conceptos que se derivan de una ontología indígena andina. En particular, la importancia de la comunidad y la complementariedad de los individuos dentro de los grupos; la visión extendida de la comunidad para abarcar la naturaleza en lugar de las comunidades humanas como algo separado de la naturaleza; la toma de decisiones basada en el consenso dentro 
de los grupos en lugar de la representación individual y el gobierno de la mayoría; vivir bien en lugar de vivir mejor; el trabajo vinculado a la reciprocidad en lugar de las relaciones capitalistas; y un sentido de santidad y espiritualidad en la vida diaria.

Como filosofía de gobernanza, Buen Vivir habla tanto de procesos, o principios éticos, como de resultados (Gudynas, 2011). Desde la perspectiva del proceso, enfatiza la toma de decisiones basada en el consenso, la inclusión de valores, costumbres y creencias locales en la formulación de políticas, el rechazo al desarrollo en favor del ser y el rechazo a la capitalización de los recursos naturales. En términos de resultados, se refiere a la realización y la protección del medio ambiente natural.

Aunque el Buen Vivir ha enfrentado desafíos en su implementación a nivel nacional (Caria \& Domínguez, 2015; Villalba, 2013), ofrece una importante alternativa a los ideales occidentales de desarrollo y gobernabilidad, frente a los problemas ambientales y sociales globales. Un ejemplo de esto es el desplazamiento desde el "desarrollo sostenible" hacia las "comunidades sostenibles" (Mischen et al., 2019). Además, a pesar de sus orígenes neoliberales como teórica de la elección pública, el enfoque de Ostrom sobre los bienes comunes también proviene de la perspectiva de la economía institucional, que ofrece una crítica de la economía clásica. Por lo tanto, si bien muchos de los principios de buena gobernanza y gobernanza pública se encuentran en su enfoque de gestionar los bienes comunes, el énfasis en el contexto está más en línea con el Buen Vivir.

Aunque se ha escrito mucho sobre el Buen Vivir como un enfoque indígena de la gobernanza la gente de Rapa Nui no es andina, sino polinesia. Comparado con el mundo andino, se escribe mucho menos sobre los sistemas de gobernanza indígenas de la Polinesia (Ban \& Frid, 2018) y la mayor parte de la literatura se refiere a la gobernanza pesquera. Lo que se ha documentado y analizado son las propias leyes consuetudinarias, el grado de inclusión de los grupos indígenas en la toma de decisiones, si los objetivos de los grupos indígenas y de los gobiernos estatales no indígenas coinciden o están en conflicto, y las bases de conocimiento de los grupos indígenas y no indígenas (véase, por ejemplo, Aburto et al., 2015, 2017; Ban \& Frid, 2018).

Tradicionalmente, muchos investigadores consideran que las estructuras de gobernanza polinesias están dominadas por caciques, lo que implica un papel central para las élites y que tienen una estructura de gobernanza fuertemente jerarquizada (por ejemplo, Kirch, 1984, 2017). Desde esta perspectiva, las reglas de gobierno se describen simplemente por la presencia de la "tradición" y la "costumbre" para racionalizar su existencia. Derivado de ideas vagamente marxistas, investigadores como Kirch (por ejemplo, 1984) comúnmente consideran que la Polinesia tiene estructuras de mando y control de arriba hacia abajo que se interpretan como "adaptaciones" a la gestión y distribución de los recursos comunes. En la narrativa de Kirch, se supone que la „élite" política y económica es la única solución a los problemas de gobernanza. Si bien es cierto que existen evidencias etnohistóricas de estructuras económicas fuertemente jerarquizadas en algunas partes de la Polinesia (por ejemplo, Hawai), hay menor claridad respecto de otras áreas (por ejemplo, Nueva Zelanda, las islas australes). Por lo tanto, no hay razón para creer que las estructuras tipo cacicazgo son un fenómeno pan-polinesio y debemos evaluar cada caso en base a la evidencia de su propio registro arqueológico e histórico. 


\section{Gobernanza indígena del contacto Preeuropeo en Rapa Nui: evidencias arqueológicas}

En los medios de comunicación populares, es común caracterizar a la sociedad rapanui preeuropea como una sociedad que no logró tener prácticas de "buena gobernanza". Como se ha visto en medios populares como la película Rapa Nui de 1994 (Reynolds \& Rose Price, 1994) y el libro "Colapso" de Diamond (2005), Rapa Nui es tratado como el ejemplo canónico de una población que fracasó catastróficamente por sus propias acciones (por ejemplo, Flenley \& Bahn 2003). En esta versión de la narrativa, se supone que las poblaciones del pasado se habrían dedicado a un culto en toda la isla a la construcción masiva de estatuas y al transporte, que requería enormes recursos para sostenerlas. Finalmente, debido a la necesidad de recursos para mantener a una población tan numerosa y a su comportamiento extravagante, se habrían agotado los recursos naturales de la isla, otrora abundantes. Así, el pueblo rapanui habría sufrido las consecuencias inevitables de sus acciones: fracaso ecológico, guerra, hambre, canibalismo, despoblación y colapso social. Como consecuencia, la población de la isla quedó atrapada en un medio ambiente degradado para siempre, en contraste con épocas anteriores de abundancia ecológica. Desde esta perspectiva, uno podría pensar que la gobernanza previa al contacto de la isla fue un fracaso.

Mientras que una historia de "colapso" de Rapa Nui se ajusta a muchas expectativas culturales sobre el comportamiento humano, nuevas investigaciones han reconfigurado en gran medida nuestro conocimiento sobre la isla (por ejemplo, Hunt \& Lipo 2006, 2007, 2008, 2009, 2011; Lipo \& Hunt 2009, 2016; Lipo et al., 2013). Gracias a excavaciones, amplios estudios de superficie, la teledetección de la estructura de los recursos insulares y la revalorización de las pruebas cronológicas, ahora está claro que simplemente no hay pruebas empíricas de una catástrofe demográfica de contacto preeuropea. En cambio, las nociones de un "colapso" previo al contacto con Europa pueden atribuirse a los conceptos erróneos de estos primeros visitantes (Hunt \& Lipo, 2011) y a la perpetuación de mitos históricos (Hunt \& Lipo 2011; Lipo \& Hunt, 2009; Mulrooney, 2012; Mulrooney et al., 2009). La evidencia arqueológica citada para un ,colapso' previo al contacto revela exactamente lo contrario: la expansión constante del uso del paisaje (Stevenson et al., 2015) hasta la llegada de los europeos, seguida de impactos bien documentados debido al contacto europeo (por ejemplo, ver Hunt \& Lipo 2011). Fundamentalmente, hay pocos indicios arqueológicos de que la población de Rapa Nui haya sido mucho mayor que la estimada de 3.000 personas que fueron testigos del contacto con europeos (Hunt, 2006; Morrison, 2012) o que haya sido sustancialmente mayor en el pasado y luego haya disminuido. Aunque se siguen haciendo afirmaciones de poblaciones mucho más grandes (por ejemplo, Diamond, 2005; Puleston et al., 2017), estas afirmaciones se basan en conjeturas o preconceptos de lo que podría haber sucedido sin vincular las afirmaciones a ninguna evidencia empírica sobre el tamaño de la población (Lipo et al., 2018). Por ejemplo, actualmente no hay evidencia de un hiato en el registro arqueológico que pueda indicar un declive masivo de la población (Mulrooney, 2013; Mulrooney et al., 2009; Stevenson et al., 2015), que sería necesario si alguna vez hubiese existido una población grande. También hay poca evidencia para suponer conflictos de gran importancia, asociado con la narrativa del "colapso", por ejemplo, esqueletos con traumatismo letal, fosas comunes, producción sistemática de armas letales o fortificaciones (Hunt \& Lipo 2009, 2001; Lipo et al., 2016). Una población de unos 3.000 individuos, en el momento de contacto, tal como describen los observadores españoles en 1770, es consistente con los estudios arqueológicos que demuestran un patrón disperso de asentamiento y uso de la tierra de baja densidad (Morrison, 2012). 
Esta nueva evidencia presenta una imagen radicalmente diferente de Rapa Nui. Más que una historia de catástrofe y colapso, la prehistoria de Rapa Nui es un estudio de caso de éxito en una isla remota y pobre en recursos. Los polinesios poblaron Rapa Nui alrededor del año 1200 d.C. como parte de la rápida expansión a través del remoto Pacífico (Hunt \& Lipo, 2006). Los colonos trajeron una lista de plantas (taro, camote, plátano, caña de azúcar, etc.) y animales (ratas, pollos) junto con una variedad de conocimientos sobre estrategias de subsistencia (pesca, cultivo) y prácticas culturales (construcción de estatuas y monumentos). A partir de estas variables, la población de Rapa Nui creció rápidamente en número a medida que la isla se transformaba de un bosque de palmeras a un paisaje agrícola y humano (Hunt \& Lipo, 2011).

Lo que sabemos por la evidencia arqueológica disponible es que las poblaciones residían en múltiples comunidades dispersas, funcionalmente redundantes, pero los grupos se beneficiaban de la interacción a través de actividades en los grandes lugares ceremoniales, los ahu (Hunt \& Lipo, 2011). Los beneficios de la interacción entre comunidades dispersas probablemente explican por qué la inversión en monumentos, aunque presente en otras partes del Pacífico, tomó una forma tan exuberante en Rapa Nui. En este lugar, la construcción de monumentos proporcionó ventajas a individuos y comunidades, sirviendo para proveer a los individuos con formas de competir al mismo tiempo que se mitigan los problemas de la incertidumbre sobre los recursos (a través del intercambio) y se reduce la inevitable competencia entre grupos a medida que la población crece (ver Hunt \& Lipo, 2011 para una discusión más profunda).

Por supuesto, las reglas sociales que facilitan las actividades de cooperación y el intercambio de recursos críticos en tiempos de necesidad son fundamentales para el éxito de un sistema de este tipo. Un problema potencial en las redes de cooperación y de intercambio de recursos surge cuando las personas se benefician sin hacer ninguna contribución sustantiva en el futuro. Este es el problema de los "aprovechadores” (free-riders, véase Blurton-Jones, 1987). A menos que se desarrolle un mecanismo para evitar tal aprovechamiento, la mayoría de los grupos seguirán siendo pequeños y relativamente igualitarios para evitar eficazmente a los tramposos (Boone, 1992). Un medio por el cual se fomenta y se hace cumplir la cooperación dentro de los grupos es a través de la señalización, por medio de la cual la participación en actividades a nivel de grupo se utiliza como una forma de marcar a aquellos que cooperan de aquellos que no cooperan (Gintis et al., 2001).

En el caso de Rapa Nui, el registro arqueológico refleja poblaciones relativamente pequeñas y de baja densidad con evidencia de cooperación consistente con tales señalizaciones, visibles a nivel de grupo, y costosas para el individuo. Los patrones de producción, transporte y exhibición de moai en la arquitectura monumental se ajustan a estas expectativas (Hunt \& Lipo 2011). Tales esfuerzos involucran empeños visuales cooperativos en los que los miembros del grupo participan para "hacer caminar" la estatua desde la cantera de Rano Raraku hasta sus posiciones en el ahu (Lipo et al. 2013). En segundo lugar, el transporte a pie de los moai proporcionó una forma ingeniosa para que grupos relativamente pequeños de personas colaboraran en el traslado incluso de las estatuas más grandes.

La evidencia arqueológica sugiere que los recursos y el paisaje de Rapa Nui fueron tratados como un bien común. Por ejemplo, un estudio reciente sobre el uso del basalto de grano fino (Simpson \& Dussubieux, 2018) revela que la comunidad tiene acceso abierto a este recurso sin 
evidencia de restricciones o control. La tierra necesaria para cultivar alimentos es igualmente ilimitada e incontrolada. Sabemos que vastas áreas de la isla fueron transformadas en jardines de mantillo de roca en respuesta a los suelos relativamente pobres en nutrientes (por ejemplo, Stevenson et al., 1999; Wozniak, 1999). La adición de roca rota al suelo (es decir, "mantillo lítico") sirvió para enriquecer los suelos lixiviados con nutrientes. De hecho, más del 10\% de la superficie total de la isla puede haber sido dedicado al cultivo de mantillo lítico (Ladefoged et al., 2013).

En general, sabemos que los isleños sobrevivieron con éxito en la isla durante 500 años hasta la llegada de los europeos. Su capacidad para hacerlo estaba vinculada a la aparición de tradiciones, arraigadas en la ascendencia cultural de los polinesios que colonizaron la isla por primera vez. Estas tradiciones, patrones de asentamiento, prácticas de cultivo y esfuerzos cooperativos en la construcción de monumentos públicos proporcionaron recursos suficientemente abundantes como para permitir a los individuos negociar los desafíos de manejar los recursos críticos comunes necesarios para la supervivencia en esta isla.

Es importante señalar que la construcción de moai y ahu fue abandonada finalmente en tiempos históricos, probablemente impulsada por la llegada de los europeos en 1722 (Simpson \& Dussubieux, 2018). Los europeos trajeron artículos exóticos que sirvieron como capital alternativo para los miembros de la comunidad, alterando radicalmente el sistema económico que fomentaba la cooperación grupal (Hunt \& Lipo, 2011). En lugar de estas actividades cooperativas de grupo crecieron otros tipos de actividades competitivas que se centraban en la adquisición de bienes privados. La competencia del Hombre Pájaro o Tangata Manu, por ejemplo, tuvo lugar en la esquina suroeste de la isla y se observó hasta la década de 1860. En este evento anual, los individuos compitieron por la adquisición del primer huevo de charrán de hollín de la temporada del islote de Motu Nui (Routledge 1919). El individuo que recuperó el huevo primero recibía privilegios para sí mismo y para su clan.

\section{Propuesta de gobernanza indígena para el Rapa Nui actual}

Cuando examinamos las recientes estructuras históricas de gobierno de Rapa Nui, encontramos sistemas que fueron impuestos por una entidad externa (Chile) para hacer operativa una estructura colonial. Esta estructura encarna las estructuras burocráticas y jerárquicas que dominaron el régimen de gobierno de la administración pública que surgió durante la industrialización. El Parque Nacional Rapa Nui (PNRN) fue creado en 1935. En 1973, la administración del parque fue cedida oficialmente a la Corporación Nacional Forestal (CONAF). Además de la gestión de la erosión del suelo y la deforestación, se encargó a CONAF la gestión del parque como recurso cultural y fuente de turismo cultural (CODEIPA, 2015: 10).

Han surgido varias críticas con respecto a la gestión del parque por parte de la CONAF, que han resultado en la creación de una propuesta para una nueva administración del parque (CODEI$P A, 2015)$. Los cargos pueden dividirse en dos categorías. En la primera categoría se abordan las deficiencias en la gestión actual del parque por parte de la CONAF, que se considera que resultan en el daño de artefactos arqueológicos, incluyendo un número inadecuado de guardaparques 
para la protección de los artefactos arqueológicos y culturales, un cobro inadecuado de las entradas y un número inadecuado de expertos en arqueología.

La segunda categoría es más antigua y se relaciona con la forma en que las tierras han sido adquiridas, utilizadas y asignadas. En 1988, 36 parcelas de 5 hectáreas fueron tomadas del Parque Nacional y repatriadas a los isleños (Ramírez, 2000). Posteriormente, la Comisión de Desarrollo de Isla de Pascua, creada por la Ley Indígena en 1993 e iniciada en junio de 1999, comenzó a distribuir parcelas a 267 familias, tierras que eran propiedad de la corporación estatal de desarrollo CORFO (IWGIA, 2012). Si bien este proceso ha dado lugar, con razón, a la devolución de tierras a la comunidad nativa de la isla, la transferencia de propiedades a particulares ha dado lugar a un conflicto sustancial por las tierras recibidas (dadas las disparidades en el valor económico), lo que ha dado lugar a mayores conflictos entre las comunidades y a la pérdida de la protección del registro arqueológico (Ramírez, 2000).

En 2014, las Comisiones Rapa Nui del CODEIPA solicitaron a CONAF que estableciera un sistema de manejo totalmente indígena para el parque. En cambio, CONAF presentó un plan de co-administración (conocido como GOSPAN), en el que el rol del pueblo rapanui era meramente consultivo (CODEIPA, 2015: 2). CODEIPA respondió con su propia propuesta para una organización llamada Ma'u Henua, cuyos objetivos específicos se resumen en la figura 3. La propuesta debía aplicarse en tres fases. La primera fase, considerada como una fase de transición, es la propuesta de GOSPAN, que permitió la co-administración entre CONAF y el pueblo rapanui representado por el Consejo Ma'u Henua. En esta fase, las operaciones continuaron siendo responsabilidad de la CONAF, sin embargo, la voz del pueblo rapanui se vio reforzada en la toma de decisiones estratégicas y en la gestión de un Fondo de Reinversión. Durante esta fase, se hizo hincapié en la representación adecuada de los rapanui y en la creación de capacidad organizativa para gestionar mejor los recursos arqueológicos y culturales.

La segunda fase, que comenzó en junio de 2018, se denominó Etapa de Derecho. En esta fase, la propuesta de Máu Henua abogaba por la creación de una Corporación de Derecho Público, administrada por los miembros del pueblo rapanui. En esta fase se invirtieron los roles y la CONAF quedó subsumida por una Corporación de Derecho Público encargada de la gestión del parque, con la asesoría de funcionarios estatales. Adicionalmente, una Ley del Parque Rapa Nui estableció nuevos límites del parque bajo la administración de la Corporación. Además de la Junta Directiva, existe una Junta Técnica Asesora que incluye miembros del Gobierno Provincial, Municipalidad de Isla de Pascua, CONAF, Consejo de Monumentos, CAM, Ministerio de Bienes Nacionales, CONADI y Sernatur (CODEIPA, 2015: 35-36). Además de estos cambios administrativos, la Etapa de Estado permitirá el desarrollo de „un sistema que permita el uso del territorio para el desarrollo de actividades económicas propias de la cultura Rapa Nui (agricultura, ganadería y pesca) compatibilizándolo con los recursos arqueológicos y la biodiversidad de la Isla" (CODEPA, 2015: 6).

La etapa final, propuesta para el año 2025, se denomina Etapa de Consolidación. Durante esta etapa, la visión es que la Junta Directiva de la Corporación esté compuesta solo por miembros del pueblo rapanui (los cuatro miembros elegidos por las familias, cuatro profesionales y un representante del Consejo de Ancianos). Además, el plan (CODEIPA, 2015: 42) establece: "El rol de apoyo y asesoría del Estado se mantendrá mediante el Consejo Técnico Asesor del Directorio, el cual seguirá integrado por las misma Instituciones de la Etapa Anterior. De esta forma se permite 
la consolidación del trabajo mancomunado entre el Estado y el Pueblo Rapa Nui, fortaleciéndose la asesoría y apoyo estratégico de las instituciones gubernamentales, lo cual es fundamental para el fortalecimiento y proyección en el tiempo de este sistema de administración"

Figura 3

Objetivos específicos de la propuesta Ma'u Henua

\section{OBJETIVOS ESPECÍFICOS}

1. Crear un Sistema de administración, mediante la creación de una Corporación, estructurada especialmente para responder a las particulares características arqueológicas y etnográficas del PNRN, considerando la condición de territorio ancestral del Pueblo Rapa Nui.

2. Establecer una estructura de funcionamiento dotada de las capacidades técnicas y humanas necesarias para asegurar la conservación y el buen manejo del recurso arqueológico, cultural y biológico presente en el PNRN. Deberá promoverse la capacitación y formación de recursos humanos locales para proyectar en el tiempo la gestión del PNRN.

3. Diseñar y establecer un sistema de financiamiento flexible, que permita la administración directa de la recaudación por venta de entradas al PNRN, con el objeto de solventar gastos operacionales e iniciativas de desarrollo del PNRN.

4. Potenciar la asesoría estratégica del Estado para garantizar el desarrollo y conservación del PNRN, tanto en su calidad de Área Silvestre Protegida, en su dimension de Monumento Histórico Nacional, y en su calidad de territorio ancestral del Pueblo Rapa Nui, mediante convenios de colaboración y asesoría técnica de sus diversas Instituciones, así como promoviendo la inversión de recursos públicos para asegurar dichos fines.

5. Asegurar el vínculo territorial entre Pueblo Rapa Nui y su cultura, mediante un sistema de gestión comunitaria del territorio ancestral, que permita armonizar el desarrollo de actividades propias de la cultura rapa nui (agricultura, ganadería, pesca, actividades ceremoniales, grupales, etc.) con el resguardo patrimonial, ambiental y el desarrollo de la actividad turística

6. Redefinir los límites del Parque Nacional, con el objeto de asegurar el debido resguardo de los recursos arqueológicos y naturales, y la gestión comunitaria del territorio para el desarrollo de actividades propias de la cultura Rapa Nui.

7. Potenciar y desarrollar el rol del Parque Nacional Rapa Nui como motor de la economía de la Isla, diversificando su oferta de visitación hacia una orientación ecoturística y sustentable, con especial énfasis en la puesta en valor del recurso patrimonial.

8. Garantizar la transparencia y comunicación entre el PNRN y el Pueblo Rapa Nui, que permita a la comunidad ser parte active de su desarrollo.

\section{Analizando la gobernanza de Ma’u Henua}


La evolución de la gobernanza de CONAF a GOSPAN y a Ma'u Henua representa una transición desde un enfoque tradicional de administración pública hacia el gobierno, pasando por un enfoque más inclusivo que enfatiza la participación y la sociedad civil (Lipo et al., de próxima aparición) y, finalmente, hacia una transición hacia la gobernanza indígena. En esta sección se realiza un análisis documental de la propuesta Máu Henua (CODEIPA, 2015) para el control indígena del Parque Nacional Rapa Nui desde la perspectiva de la buena gobernanza, la gobernanza publica de los bienes comunes y el Buen Vivir.

\section{Gobernanza buena, pública y común}

Los principios de rendición de cuentas, participación y estado de derecho son compartidos por la buena gobernanza, la gobernanza pública y la gobernanza de los bienes comunes, y los tres están presentes en la propuesta de Ma'u Henua. Aunque en la propuesta no se menciona específicamente la rendición de cuentas ni cómo se gestionará, se mantienen muchas de las estructuras jerárquicas, típicamente asociadas con la rendición de cuentas, en la forma de la burocracia de la CONAF. La participación es una de las fuerzas motivadoras detrás del movimiento Ma'u Henua. Además, se prevé que la participación avance. „El proceso de Consulta Indígena de la propuesta Ma'u Henua debe ser vinculante, debiendo orientarse a la participación de la totalidad de los miembros del pueblo Rapa Nui, debiendo tener una duración que permita el efectivo debate y validación social de la propuesta" (CODEIPA 2015: 24). El estado de derecho habla de la estructura institucional más amplia de la que Ma'u Henua forma parte. Al igual que la transparencia, el estado de derecho puede considerarse inherentemente entrelazado con la rendición de cuentas. La rendición de cuentas vertical depende del estado de derecho (O'Donnell, 2004). El estado de derecho es invocado regularmente en la propuesta desde una perspectiva histórica (es decir, las leyes chilenas aprobadas en relación con Rapa Nui), las leyes que rigen la creación de un nuevo órgano de gobierno y una perspectiva de legitimidad externa, como se discute más adelante.

Además de abordar estos principios compartidos, la propuesta de Ma'u Henua aborda los otros conceptos de buena gobernanza pública. El concepto de transparencia se encuentra en uno de sus ocho objetivos específicos: „Garantizar la transparencia y comunicación entre el PNRN y el Pueblo Rapa Nui, que permita a la comunidad ser parte activa de su desarrollo" (CODEIPA 2015: 8). En términos de eficiencia, existe la creencia de que la reestructuración propuesta de la administración conducirá a una administración más eficiente del PNRN. El compromiso y la asociación se evidencian a través de la Junta Directiva y el establecimiento de un Consejo Asesor Técnico. Finalmente, las interconexiones globales son reconocidas en la propuesta ya que Rapa Nui es un importante destino turístico. El turismo es percibido como una amenaza, pero también como una oportunidad económica para Rapa Nui. De hecho, toda una sección de la propuesta está dedicada al "Turismo e Infraestructura”. De particular interés es el desarrollo del ecoturismo y el turismo sostenible.

Pasando de los principios de buena gobernanza a los principios de gestión de los bienes comunes, la propuesta de Ma'u Henua se centra en la creación de un sistema de derecho indígena para el parque y la reevaluación de sus límites. Un aspecto central de la propuesta de Máu Henua es ver estas acciones propuestas a través de la perspectiva de la gobernanza del patrimonio común, los límites (principio $n^{\circ} 1$ ) y la forma en que se determinarán. Los límites físicos del área común están en flujo actualmente. Debido a los esfuerzos de privatización de los años 90, parte 
de la tierra que históricamente había sido común fue vendida o entregada a familias individuales. Parte de la propuesta de Ma'u Henua es convertir esas tierras de nuevo en áreas comunes.

El segundo principio de gobernanza de los bienes comunes se refiere a la necesidad de contar con normas que se ajusten a las necesidades y condiciones locales. Una motivación significativa de la propuesta de Máu Henua es poner el control de los recursos en manos de aquellos que mejor saben cómo manejarlos. Tradicionalmente, la tierra ha sido administrada por clanes ancestrales. Esta conexión de la tierra con la familia es notada por Desing (2009) como uno de los aspectos fundamentales de la cultura rapanui. La propuesta (CODEIPA 2015: 32) establece: "Se deberán fomentar además el desarrollo de actividades que rescaten el conocimiento tradicional y el vínculo con los territorios ancestrales. En esta línea, se propone la demarcación de los diferentes clanes, permitiendo generar y rescatar la identificación de los descendientes con sus respectivos sectores (mata)".

El tercer principio refleja la necesidad de una toma de decisiones cooperativa con respecto a los bienes comunes. En la Etapa 3 de la propuesta Máu Henua, la Junta Directiva del Parque consiste de 11 miembros: cuatro elegidos de las 36 familias tradicionales, cuatro profesionales rapanui elegidos por la población general del pueblo rapanui, y un representante del Consejo de Ancianos. Además de esta estructura, la propuesta menciona frecuentemente el hecho de que la toma de decisiones colectiva es parte de la cultura rapanui.

Los autores reconocen que la propia propuesta, y varios de los elementos que contiene, deben ser aceptados por las autoridades chilenas. Como tal, reconoce la importancia de la legitimidad externa (principio $n^{\circ} 4$ ). Esto es importante para la implementación del resto de los principios de gobierno de los bienes comunes, que se refieren a la aplicación de las normas de conducta. Aunque no se abordan explícitamente en la propuesta, la falta de inclusión tiene sentido, ya que los cuatro primeros principios establecen la estructura de la elaboración de normas, y los cuatro últimos se refieren a la aplicación de las propias normas. Será importante que Máu Henua aborde estos principios al principio del proceso.

\section{Gobernanza del Buen Vivir}

La toma de decisiones colectiva es la piedra angular de la propuesta de Máu Henua. En lo que respecta a los aspectos, encaja bien con algunos orientados al proceso de Buen Vivir. La propuesta también hace clara referencia a la inclusión de los valores, costumbres y creencias locales en la formulación de políticas, especialmente cuando se trata de la tenencia de la tierra. Sin embargo, mientras que la toma de decisiones colectiva está referenciada y hay planes para continuar con un enfoque de consulta en red con organizaciones externas, la estructura organizacional en la propuesta sigue siendo jerárquica y burocrática. No está claro si la toma de decisiones se basa en el consenso o en la mayoría, pero la propuesta de Máu Henua hace la distinción entre la tradicional toma de decisiones polinesia y las prácticas chilenas de toma de decisiones, que se remontan a la década de 1920 y a la época en que la isla estaba gobernada por la Armada de Chile, que se consideran basadas en los derechos individuales y la propiedad privada. Esta distinción lleva a creer que la toma de decisiones colectiva tradicional está más orientada al consenso que a la decisión basado en el principio de la mayoría. 
Sin embargo, en vista de los otros aspectos del Buen Vivir orientados al proceso, un rechazo al desarrollo a favor del ser y un rechazo a la capitalización de los recursos naturales, la propuesta es contraria al Buen Vivir. Los términos "desarrollo" y "desarrollar" se mencionan decenas de veces y se incluyen en seis de los ocho objetivos específicos de la propuesta. Si bien varios de los usos de este término son genéricos y no se relacionan necesariamente con el desarrollo como un objetivo económico, el desarrollo también se menciona junto con la capitalización de los recursos naturales y culturales en el Objetivo Específico n 3. La utilización del Parque como „motor de la economía de la isla" se menciona también en el Objetivo Específico n 7 . Además, un porcentaje significativo de la propuesta (18 de las 70 páginas) se dedica a discutir el turismo y la financiación del PNRN.

Con respecto a los resultados del cumplimiento y la preservación del medio ambiente, la propuesta Ma'u Henua no da muchas luces sobre lo que el cumplimiento podría significar en el contexto de Rapa Nui. Aunque hay varias menciones de la importancia de preservar y desarrollar la cultura rapanui, no está claro qué representa esa cultura más allá de las reglas de tenencia de la tierra, la toma de decisiones colectivas y las "actividades“ culturales. La preservación del medio ambiente es claramente un resultado previsto, ya que en los Objetivos Específicos se mencionan la conservación y la gestión de los recursos biológicos, un Área de Vida Silvestre Protegida, y el ecoturismo y el turismo sostenible.

\section{Análisis de la gobernanza Preeuropea}

El registro arqueológico es el registro agregado contemporáneo de las consecuencias empíricas de la interacción humana con el medio ambiente. Dado que no incluye el comportamiento por definición, el aprendizaje sobre la gobernanza debe hacerse generando hipótesis sobre cómo los isleños se las arreglaron para hacer frente a las limitaciones naturales de la isla (por ejemplo, el tamaño, los recursos limitados, el aislamiento, los suelos pobres) a través de la forma en que las comunidades se estructuraron e interactuaron entre sí y con sus miembros. En el caso de Rapa Nui, si tomamos como punto de partida nuestras hipótesis actuales sobre su éxito preeuropeo, evaluamos posteriormente el grado en que las características del registro (composición, configuración espacial) pueden explicarse en términos de los requisitos clave para el bien común público y la gobernanza del Buen Vivir.

En base a la naturaleza de los recursos y los desafíos que enfrentan las comunidades que dependen de los recursos comunes, podemos inferir una serie de atributos sobre la gobernanza arqueológica rapanui en el contexto de los rasgos de la gobernanza buena/pública. En cuanto a la rendición de cuentas, no tenemos pruebas de una aplicación sistemática de la ley. En cambio, la evidencia arqueológica y etnohistórica temprana es consistente con la noción de que el Rapa Nui preeuropeo dependía principalmente de la interacción interpersonal y la negociación, al igual que el enfoque de rendición de cuentas que se observa en los enfoques de gobernanza de redes de hoy en día. Por la naturaleza pública y cooperativa de la construcción de monumentos, las contribuciones individuales a la comunidad se hicieron transparentes: uno podía fácilmente validar si se adhería a las reglas de la comunidad observando la participación y los resultados. Sobre la base de las primeras cuentas europeas, parece que la participación en la gobernanza carece de una estructura vertical sólida. En cambio, la gobernanza fue colaborativa e inclusiva. A diferencia de los sistemas contemporáneos de gobierno más formales, los rapanui de pre-contacto utilizaban 
la tradición y las pautas culturales para guiar el comportamiento (en lugar de la ley formal). Finalmente, dadas las características compartidas que se observan en toda la isla, junto con las áreas domésticas localizadas (por ejemplo, Morrison 2012) y la variabilidad en los artefactos estilísticos (por ejemplo, Lipo, et al. 2010), sabemos que la población de la isla estaba limitada localmente e interactuaba con los vecinos inmediatos a través de redes de baja conectividad en toda la isla (Lipo et al., 2019). Estas conclusiones indican claramente la falta de una estructura jerárquica en la toma de decisiones que haga que la gobernanza sea eficiente; en cambio, las actividades en toda la isla deben haber surgido a través de procesos elaborados que incluyan numerosas y continuas interacciones y negociaciones locales.

Ostrom (1990) también proporciona un marco conceptual útil para generar hipótesis sobre la necesidad de gobernanza para la gestión de los recursos comunes. No es de extrañar, dados los 500 años de éxito, que lo que ahora conocemos sobre la gobernanza de Rapa Nui se ajuste a estos principios (Cuadro $N^{\circ}$ 2). Por ejemplo, las condiciones necesarias para el principio 1 parecen estar bien cumplidas. Los grupos están bien definidos en el paisaje por conjuntos agregados de características domésticas (hornos, casas, jardines amurallados, campo de acolchado) en el paisaje que rodea a los monumentos de ahu y moai (Morrison, 2011). Cada ahu definió efectivamente el esfuerzo comunal del grupo y permitió la identidad entre grupos. Es probable que el principio 2 se cumpla por el hecho de que la inversión en monumentos y las actividades domésticas están correlacionadas con la abundancia y fiabilidad de los recursos locales a través de los cuales la comunidad. La evidencia del análisis genético (Dudgeon et al., 2016), la osteología (Gill et al., 1983; Gill \& Owsley, 1993) y los análisis estilísticos de las herramientas de la obsidiana (Lipo et al., 2010) muestran que las poblaciones estaban en gran medida confinadas a interacciones espaciales locales, más que a interacciones más fluidas en toda la isla.

\section{Cuadro $\mathrm{N}^{\circ} 1$}

Governanza buena/pública en la Rapa nui pre-contacto europeo y la propuesta Máu Henua

\begin{tabular}{|l|l|l|}
\hline Elemento Governanza & \multicolumn{1}{|c|}{ Pre-contacto europeo } & \multicolumn{1}{c|}{ Ma'u Henua } \\
\hline Rendición de cuentas & Interpersonal & $\begin{array}{l}\text { Interpersonal; jerárquica/adminis- } \\
\text { trativa; de mercado; democrática }\end{array}$ \\
\hline Transparencia & $\begin{array}{l}\text { Desconocida, aunque las accio- } \\
\text { nes cooperativas de los miembros } \\
\text { de la comunidad pueden ser vis- } \\
\text { tas entre ellos }\end{array}$ & $\begin{array}{l}\text { Transparencia en la comunicación } \\
\text { mencionada en la lista de objeti- } \\
\text { vos específicos. }\end{array}$ \\
\hline Participación & $\begin{array}{l}\text { Colaborativa e inclusive. No hay } \\
\text { una estructura de arriba hacia } \\
\text { abajo clara. }\end{array}$ & $\begin{array}{l}\text { Junta Administrativa- } \\
\text { Estructurada, representación de } \\
\text { la comunidad indígena }\end{array}$ \\
\hline Principio de legalidad & Basado en la tradición & Estatutario; Ley Chilena \\
\hline Eficiencia & $\begin{array}{l}\text { Ineficiente en la escala de la isla: } \\
\text { governanza hyperlocal con pocas } \\
\text { interacciones entre comunidades. }\end{array}$ & $\begin{array}{l}\text { Creencia de que la reestructura- } \\
\text { ción traerá mayor eficiencia. }\end{array}$ \\
\hline Redes & $\begin{array}{l}\text { Comunidades limitadas espacial- } \\
\text { mente conectadas con vecinos de } \\
\text { inmediatos a locales. }\end{array}$ & Junta de Asesoramiento Técnico \\
\hline
\end{tabular}




\begin{tabular}{|l|l|l|}
\hline Elemento Governanza & \multicolumn{1}{|c|}{ Pre-contacto europeo } & \multicolumn{1}{c|}{ Ma'u Henua } \\
\hline Globalización & No aplica. & $\begin{array}{l}\text { Preocupación por el turismo, cam- } \\
\text { bio climático. }\end{array}$ \\
\hline
\end{tabular}

Elaboración propia.

\section{Cuadro $\mathrm{N}^{\circ} 2$}

Gobernanza de bienes comunes en la Rapa Nui previa al contacto europeo y la propuesta Ma'u Henua

\begin{tabular}{|c|c|c|}
\hline Elemento Governanza & Pre-contacto europeo & Ma'u Henua \\
\hline Límites & $\begin{array}{l}\text { Definidos por la ubicación de los } \\
\text { ahu y moai. }\end{array}$ & $\begin{array}{l}\text { Fluidos y poco claros, pero un } \\
\text { foco de la propuesta. }\end{array}$ \\
\hline Necesidades locales & $\begin{array}{l}\text { Determinadas por disponibilidad y } \\
\text { restricciones de recursos locales. }\end{array}$ & $\begin{array}{l}\text { Potencial de institucionalización } \\
\text { de costumbres tradicionales. }\end{array}$ \\
\hline $\begin{array}{l}\text { Toma de decisiones } \\
\text { democrática }\end{array}$ & $\begin{array}{l}\text { Todos los miembros de la comuni- } \\
\text { dad participan de la toma de de- } \\
\text { cisiones. }\end{array}$ & Junta Administrativa. \\
\hline Legitimidad externa & No aplica debido al aislamiento. & Autorizada por la ley Chilena. \\
\hline $\begin{array}{l}\text { Supervisión de com- } \\
\text { portamiento }\end{array}$ & $\begin{array}{l}\text { Inversiones y uso compartido su- } \\
\text { pervisado por los observadores lo- } \\
\text { cales dentro de cada comunidad. }\end{array}$ & $\begin{array}{l}\text { Por determinarse en la implemen- } \\
\text { tación. }\end{array}$ \\
\hline Sanciones graduales & $\begin{array}{l}\text { Desconocidas, aunque el bajo ni- } \\
\text { vel de violencia letal sugiere san- } \\
\text { ciones graduadas adecuadamen- } \\
\text { te. }\end{array}$ & $\begin{array}{l}\text { Por determinarse en la implemen- } \\
\text { tación. }\end{array}$ \\
\hline $\begin{array}{l}\text { Resolución de conflic- } \\
\text { tos }\end{array}$ & $\begin{array}{l}\text { Conflicto mediado por la comuni- } \\
\text { dad local. }\end{array}$ & $\begin{array}{l}\text { Por determinarse en la implemen- } \\
\text { tación. }\end{array}$ \\
\hline Niveles & No aplica. & $\begin{array}{l}\text { Por determinarse en la implemen- } \\
\text { tación. }\end{array}$ \\
\hline
\end{tabular}

Elaboración propia

Con respecto al principio $n^{\circ} 3$, nuestro entendimiento actual de la isla apunta a la falta de una jerarquía fuerte de arriba hacia abajo. A pesar de las suposiciones sobre el papel de las élites y los „jefes” en la toma de decisiones (por ejemplo, Kirch, 2017), los primeros observadores etnohistóricos afirman sistemáticamente la falta de gobernantes dominantes. El registro arqueológico también carece de evidencia directa de control sobre la distribución de los recursos (Simpson y Dussubieux, 2018; Simpson et al., 2018). Por lo tanto, parece como si todos los miembros de la comunidad formaran la base de los miembros del gobierno en lugar de algún tipo de líder arbitrario o subconjunto de isleños. 
La construcción de los complejos de ahu y moai parece ser una de las principales formas en que los isleños cumplieron el requisito del principio $n^{\circ} 5$. Dado que la inversión en la construcción de estos monumentos era necesariamente colaborativa y pública, todos los miembros pudieron verificar las contribuciones de los demás. Con respecto a los principios $n^{\circ} 6,7$ y 8 , las controversias parecen haberse resuelto pacíficamente mediante un proceso de negociación entre individuos de cada comunidad (por ejemplo, Forster 1774 citado en Jakubowska 2014).

Comparando los objetivos de un enfoque Buen Vivir con nuestra comprensión de las características de gobernanza del contacto preeuropeo con Rapa Nui, podemos ver áreas de coincidencia, pero también diferencias significativas (Cuadro $N^{\circ} 3$ ). Por ejemplo, la preferencia por la toma de decisiones basada en el consenso, que es una característica del Buen Vivir también es evidente en Rapa Nui antes del contacto, dada la falta de evidencia de jerarquía y control de arriba hacia abajo. También vemos que el énfasis común en el papel de los valores, las costumbres y las creencias en la formulación de políticas aparece en las tradiciones de larga data observadas en el registro arqueológico. Pero hay diferencias también. Mientras que Buen Vivir rechaza el desarrollo y la capitalización de los recursos naturales, el registro previo al contacto sugiere una historia de continuo crecimiento y transformación de la isla para apoyar a las poblaciones, así como muestras visibles de riqueza en forma de construcciones de moai y ahu (Hunt y Lipo 2017). Un área que es central para el Buen Vivir pero de la cual no tenemos información para Rapa Nui antes de la llegada de europeos, es el enfoque en el cumplimiento como principio de gobernanza.

\section{Cuadro $\mathrm{N}^{\circ} 3$}

Governanza de buen vivir en la Rapa Nui previa al contacto europeo y la propuesta Ma'u Henua

\begin{tabular}{|c|c|c|}
\hline Elemento Governanza & Pre-contacto europeo & Ma'u Henua \\
\hline $\begin{array}{l}\text { Toma de decisiones } \\
\text { basada en el consenso }\end{array}$ & $\begin{array}{l}\text { No hay evidencia de jerarquías y control de } \\
\text { arriba hacia abajo. } \\
\text { Decisiones basadas en la comunidad. }\end{array}$ & $\begin{array}{l}\text { Menciones reiteradas } \\
\text { a la toma de decisio- } \\
\text { nes colectiva. }\end{array}$ \\
\hline $\begin{array}{l}\text { Valores/costumbres/ } \\
\text { creencias en la elabo- } \\
\text { ración de políticas }\end{array}$ & $\begin{array}{l}\text { Utilización de tradiciones de largo aliento } \\
\text { para dirigir las elecciones y prácticas. }\end{array}$ & $\begin{array}{l}\text { Sí, en especial respec- } \\
\text { to de las prácticas de } \\
\text { propiedad de la tierra. }\end{array}$ \\
\hline Rechazo del desarrollo & $\begin{array}{l}\text { No: el crecimiento de las comunidades de la } \\
\text { isla se evidencia a través de la transformación } \\
\text { de la isla para sostener a la población. }\end{array}$ & No \\
\hline $\begin{array}{l}\text { Rechazo de la capitali- } \\
\text { zación de los recursos } \\
\text { naturales }\end{array}$ & $\begin{array}{l}\text { No: los Moai y ahu servían como "capital", ya } \\
\text { que mostraban riqueza. Tras el contacto ini- } \\
\text { cial, los recursos naturales y culturales se co- } \\
\text { merciaban libremente. }\end{array}$ & No \\
\hline $\begin{array}{l}\text { Objetivo de cumpli- } \\
\text { miento }\end{array}$ & Desconocido & No \\
\hline $\begin{array}{l}\text { Objetivo de protección } \\
\text { medioambiental }\end{array}$ & $\begin{array}{l}\text { No: la transformación medioambiental se } \\
\text { efectuaba para volver a la isla sostenible para } \\
\text { las comunidades. }\end{array}$ & $\begin{array}{l}\text { Sí, en el marco de la } \\
\text { conservación biológi- } \\
\text { ca y ecoturismo. }\end{array}$ \\
\hline
\end{tabular}


El principio de protección del medio ambiente plantea preguntas interesantes para el Rapa Nui pre-europeo. Por un lado, el ambiente pre-humano de la isla fue radicalmente alterado por los coIonos polinesios que talaban y quemaban el bosque para crear áreas de cultivo (batatas, taro, plátanos, caña de azúcar). Tales cambios también resultaron en la pérdida de las poblaciones de aves que habitaban el bosque nativo de palmeras. Mientras que estos cambios ambientales han sido considerados una catástrofe ecológica por algunos (por ejemplo, Diamond 2005), la evidencia actual apunta al hecho de que estos cambios incrementaron la capacidad de carga de la isla para los humanos (Hunt \& Lipo, 2011, 2013). Por lo tanto, el registro arqueológico no muestra evidencia de protección del medio ambiente per se, sino que el cambio ambiental se hizo de una manera que condujo a la sostenibilidad de las comunidades humanas que dependían de los recursos de la isla.

\section{Resumen y conclusiones}

Aunque como concepto la gobernanza es una noción moderna, la práctica de gobernanza es tan antigua como la historia de la humanidad. Elementos de buena gobernanza, gobernanza pública, gobernanza de bienes comunes, y del Buen Vivir se pueden encontrar en la reciente propuesta de Ma'u Henua, una organización diseñada para gobernar el recurso común del PNRN. Lo que ahora se rige por las normas y reglamentos de la organización y la ley chilena alguna vez fue gobernada por clanes y costumbres. El paso del gobierno jerárquico a la gobernanza participativa ofrece una oportunidad para que la gobernanza indígena se fusione con la gobernanza moderna. Por ejemplo, la rendición de cuentas en tiempos previos al contacto con los europeos era en gran medida interpersonal. A medida que las sociedades modernas construían burocracias, la rendición de cuentas se convirtió en parte de esa estructura jerárquica. Si bien esta responsabilidad administrativa sigue existiendo, la gobernanza pública moderna, basada en redes y relaciones, depende una vez más de la responsabilidad interpersonal.

Mientras que la rendición de cuentas moderna incorpora muchos de los mismos elementos que se observan en la rendición de cuentas de los contactos preeuropeos, otros aspectos de la gobernanza son considerablemente diferentes hoy en día. Por ejemplo, el paisaje moderno de Rapa Nui es muy distinto al paisaje del pasado. En el pasado, la gobernanza era hiperlocal, con límites establecidos por la ubicación de los ahu y moai. Hoy, aunque los límites del Parque están cambiando, el área a ser gobernada como un recurso común es una única gran extensión de tierra para ser compartida por todas las familias rapanui. Los límites para las familias son complejos y fluidos dadas las conexiones intermatrimoniales y externas. Del mismo modo, los mecanismos de gobernanza contemporáneos se han formalizado más y están sujetos a la aprobación de personas ajenas a la organización. Las preocupaciones sobre el uso de los recursos naturales reflejan los impactos del turismo mundial e influyen en las decisiones necesarias para adaptarse a los cambios climáticos mundiales previstos. Si bien el patrimonio cultural de la isla sigue siendo local, los factores e influencias mundiales están influyendo en las decisiones y deben tenerse en cuenta en el desarrollo de la buena gobernanza. Por lo tanto, si bien la gobernanza tradicional ofrece conocimientos sobre lugares específicos y modalidades de adopción de decisiones culturalmente pertinentes, se verá desafiada por fuerzas externas con las que no tuvo que lidiar en el pasado.

Es posible que esta sea la razón por la que la propuesta de Máu Henua se basa tanto en el lenguaje moderno de la gobernanza y mucho menos en el lenguaje que se encuentra en el Buen 
Vivir. Con un enfoque en el desarrollo y la capitalización de los recursos naturales y culturales, la propuesta difiere significativamente de un enfoque de Buen Vivir que rechaza tanto la noción de desarrollo como la de capitalización de los recursos naturales. Tampoco habla del concepto de cumplimiento. Sin embargo, se basa en valores, costumbres y creencias en la formulación de políticas, subraya la importancia de la toma de decisiones colectiva (aunque dentro de una estructura jerárquica y burocrática) y la importancia de la preservación del medio ambiente (dentro del concepto de ecoturismo).

Aunque no era el propósito de este artículo suponer las razones para el uso de la buena gobernanza, gobernanza pública, la gobernanza de comunes, o el lenguaje del Buen Vivir, hay varias posibilidades de por qué la propuesta se basa en gran medida en el lenguaje de la buena gobernanza/pública y es contraria a aspectos importantes del Buen Vivir. En primer lugar, como se mencionó anteriormente, puede deberse al reconocimiento de que los modos tradicionales de gobernanza no serán suficientes en un mundo globalizado y en red. En segundo lugar, podría reflejar el proceso de colonización que comenzó en el siglo XIX y tuvo un efecto inmediato en la cultura de Rapa Nui. Tercero, debido a que los rapanui son de ascendencia polinesia y actualmente están fuertemente identificados con la cultura polinesia, el marco indígena del Buen Vivir no se alinea con la gobernanza tradicional polinesia. Es necesario seguir explorando los principios en los que se basa la gobernanza tradicional de Rapa Nui para responder a esta pregunta de manera más completa.

En general, nuestro nuevo entendimiento de Rapa Nui desafía la idea de que los sistemas de gobernanza tradicionales, basados en lo local, son intrínsecamente defectuosos. Con nuevos conocimientos, sin embargo, tenemos áreas productivas a considerar para desarrollar la buena gobernanza pública de los bienes comunes. De nuestros estudios del registro arqueológico, podemos ver que el éxito de Rapa Nui frente a la incertidumbre y las limitaciones (sociales, ambientales y geográficas) se derivó de las estructuras de gobierno en las que la información y los recursos fueron compartidos entre los individuos y las comunidades locales. A través de la interacción de múltiples comunidades dispersas, las innovaciones se difundieron fácilmente, y la escasez de recursos se resolvió mediante esfuerzos integrados de colaboración marcados por actividades relacionadas con la construcción y el transporte de moai. Siguiendo el ejemplo de la prehistoria de Rapa Nui, sugerimos que cualquier actividad regular (por ejemplo, competencias, rituales, reuniones) que reúna a las comunidades y que promueva la cooperación dentro del grupo proporcionará un beneficio directo a todos los que participen. Con las estructuras locales, los grupos que tienen una mayor cooperación lo harán mejor que los que no la tienen, particularmente en el contexto de la incertidumbre. A la escala de la isla, entonces, la competencia entre estos grupos, que también participan en la cooperación intergrupal, conducirá a un sistema global sostenible para la isla. A través de las limitaciones y las condiciones locales que enfrentan las poblaciones que viven en Rapa Nui, tenemos un ejemplo de gobernanza resiliente y adaptable en su máxima expresión.

Con la combinación de mecanismos de gobierno tradicionales y modernos en la organización Ma'u Henua, tenemos razones para ser cautelosamente optimistas sobre el futuro de Rapa Nui. Ma'u Henua evita algunos de los problemas de gobernanza tradicional que se observan en la gestión de la pesca en toda Oceanía al no depender únicamente de los conocimientos y la gobernanza tradicionales. Aunque reconocida por la legislación chilena, la toma de decisiones, las 
sanciones y la aplicación de la ley pueden basarse en mecanismos de gobernanza tradicionales. Esta combinación de enfoques permitirá hacer frente a las incertidumbres que plantea el inminente cambio climático. A medida que la isla comienza a encontrar condiciones ambientales que se desvían de aquellas en las que tradicionalmente se han basado las acciones, la gobernanza de este recurso común debe volverse cada vez más adaptable y dinámica. De esta manera, Rapa Nui vuelve a ser un sistema cultural ejemplar de buena gobernanza que muestra caminos hacia el éxito a largo plazo.

\section{Bibliografia}

ABURTO, J.A., GAYMER, C.F. y CUNDILL, G. Towards local governance of marine resources and ecosystems on Easter Island. Aquatic Conservation: Marine and Freshwater Ecosystems, 2017, vol. 27, n² 2, p. 353-371. https://doi.org/10.1002/aqc.2665

ABURTO, J.A., GAYMER, C.F., HAOA, S. y GONZÁLEZ, L. Management of marine resources through a local governance perspective: Re-implementation of traditions for marine resource recovery on Easter Island. Ocean \& Coastal Management, 2015, n 116, p. 108-115. https://doi.org/10.1016/j. ocecoaman.2015.07.008

BAN, N. C. y FRID, A. Indigenous peoples' rights and marine protected areas. Marine Policy, 2018, n 87, p. 180-185. https://doi.org/10.1016/j.marpol.2017.10.020

BEVIR, M. Key concepts in governance. Los Ángeles: Sage, 2009.

BIBLIOTECA DEL CONGRESO NACIONAL DE CHILE. Reportes Estadísticos Comunales, 2015. Recuperado de: http://reportescomunales.bcn.cl/2015/index.php/Isla_de_Pascua.

BLURTON JONES, N.G.. Tolerated theft, suggestions about the ecology and evolution of sharing, hoarding and scrounging. Social Science Information, 1987, n² 26, p. 31-54.

BOONE, J. Competition, conflict, and development of social hierarchies, in: SMITH, E.A., y WINTERHALDER, B. (Eds.), Evolutionary Ecology and Human Behavior, Nueva York: Aldine de Gruyter, 1992, p. 301-338.

BOVAIRD, T. Public governance: balancing stakeholder power in a network society. International Review of Administrative Sciences, 2005, n 71, p. 217-228. https://doi.org/10.1177/0020852305053881

CARIA, S., y DOMÍNGUEZ, R.. Ecuador's Buen vivir: A New Ideology for Development. $\quad \mathrm{L}$ a $\mathrm{t}$ i $\mathrm{n}$ American Perspectives, 2016, vol. 43, n 1, p 18-33. https://doi.org/10.1177/0094582X15611126

CLARK, B. Political Economy: A Comparative Approach. 2a ed. Westport: Praeger, 1998.

CODEIPA. Máu Henua: Propuesta De Nueva Administración Parque Nacional Rapa Nui, 2005. Recuperado de: http://ciperchile.cl/wp-content/uploads/PROPUESTA-MAU-HENUA.pdf. 
COHA. Difficult Times for Chile's Easter Island, 2011 Recuperado de: http://www.coha.org/difficult-times-for-chiles-easter-island/.

DELAUNE, G. Rapa Nui on the Verge: Easter Island's Struggles with Integration and Globalization in the Information Age. Berkeley Planning Journal, 2012, n² 25, p. 126-139.

DIAMOND, J. Collapse: How Societies Choose to Fail or Succeed. Nueva York: Viking Press, 2005.

DUDGEON, J.V., COMMENDADOR, A.S., y TROMP, M.. Archaeogenetics and paleodemographic estimation of founding populations: Features of residential geography on Rapa Nui, en: GILL, G.W. y STEFAN, V.H. (Eds.), Skeletal Biology of the Ancient Rapanui (Easter Islanders), Cambridge Studies in Biological and Evolutionary Anthropology. Cambridge: Cambridge University Press, 2016, pp. 202-221. https://doi.org/10.1017/СВО9781139151856.012

FISCHER, S.R.. Island at the End of the World: The turbulent history of Easter Island. Chicago: University of Chicago Press, 2005.

FLENLEY J., y Bahn, P.. The Enigmas of Easter Island. Cambridge: Oxford University Press, 2003.

GILL, G.W. y OWSLEY, D.W. Human osteology of Rapanui, en: FISCHER, S.R. (Ed.), Easter Island Studies. Oxbow Monograph 32. Oxford: Oxbow Books, 1993

GILL, G.W., OWSLEY, D.W., y BAKER, S.J. Cranio-metric evaluation of prehistoric Easter Island populations. American Journal of Physical Anthropology, 1983, n 60, p. 197.

GINTIS, H., SMITH, E.A., y BOWLES, S. Costly Signaling and Cooperation. Journal of Theoretical Biology, 2001, n² 213, p. 103-119.

GRUGEL, J., y RIGGIROZZI, P. Post-neoliberalism in Latin America: Rebuilding and Reclaiming the State after Crisis. Development and Change, 2012, vol. 43, n 1, p. 1-21. https://doi.org/10.1111/ j.1467-7660.2011.01746.x

GUDYNAS, E. Buen Vivir: Today's tomorrow. Development, 2011, vol. 54, n 4, p. 441-447. https:// doi.org/10.1057/dev.2011.86

HUNT, T.L. Rethinking the Fall of Easter Island. American Scientist, 2006, n 94, p. 412-419.

HUNT, T.L. y LIPO, C.P. The statues that walked: unraveling the mystery of Easter Island. Nueva York: Free Press, 2011.

HUNT, T.L. y LIPO, C.P. Ecological catastrophe, collapse, and the myth of "Ecocide" on Rapa Nui (Easter Island), en: MCANANY, P.A. y YOFFEE, N. (Eds.), Ecological Catastrophe, Collapse, and the Myth of "Ecocide" on Rapa Nui (Easter Island).Nueva York: Cambridge University Press, 2011, p. 21-44. 
HUNT, T. L. y LIPO, C.P. The Human Transformation of Rapa Nui (Easter Island, Pacific Ocean). En: LARRUE, S, (ed.). Biodiversity and Societies in the Pacific Islands. Aix-en-Provence Presses Universitaires de Provence, 2013, p. 167-184.

HUNT, T.L. y LIPO, C.P. Late Colonization of Easter Island. Science, 2016, n³11, p. 1603-1606.

HUNT, T. L. y LIPO, C.P. Rapa Nui (Easter Island). En: E. E. COCHRANE y T. L. HUNT (eds.) The Oxford Handbook of Prehistoric Oceania. Nueva York: Oxford University Press, 2017.

HUNT, T.L. y LIPO, C.P. Chronology, deforestation, and "collapse:" Evidence vs. faith in Rapa Nui prehistory Rapa Nui Journal, 2017, n² 21, p. 85-97.

HUNT, T.L. y LIPO, C. Evidence for a Shorter Chronology on Rapa Nui (Easter Island). The Journal of Island and Coastal Archaeology, 2018, n 3, 140-148.

INSTITUTO NACIONAL DE ESTADÍSTICAS. Síntesis de Resultados Censo 2017, 2017. Recuperado de: https://www.censo2017.cl/descargas/home/sintesis-de-resultados-censo2017.pdf. Instituo Nacional de Estadísicas, Santiago, Chile.

IWGIA. The human rights of the Rapa Nui People on Easter Island: Report of the international Observers' Mission to Rapa Nui 2011, 2012. Recuperado de: https://www.iwgia.org/images/publications//0597_Informe_RAPA_NUI_IGIA-Observatorio_English_FINAL.pdf. International Work Group for Indigenous Affairs.

JAKUBOWSKA, Z. Still More to Discover: Easter Island in an Unknown Manuscript by the Forsters from the 18th Century. Varsovia: Muzeum Historii Polskiego Ruchu Ludowego, Warsaw, 2014

KIM, P.S., HALLIGAN, J., CHO, N., OH, C.H. y EIKENBERRY, A.M. Toward participatory and transparent governance: Report on the sixth global forum on reinventing government. Public Administration Review, 2005, n65, p. 646-654.

KIRCH, P.V. The Evolution of Polynesian Chiefdoms. Cambridge: Cambridge University Press, 1984.

KIRCH, P.V. On the Road of the Winds: An Archaeological History of the Pacific Islands before European Contact, Revised and Expanded Edition. Berkeley: University of California Press, 2017.

LADEFOGED, T.N., FLAWS, A. y STEVENSON, C.M. The Distribution of Rock Gardens on Rapa Nui (Easter Island) as Determined from Satellite Imagery. Journal of Archaeological Science, 2013, $\mathrm{n}^{\circ}$ 40, p. 1203-1212.

LIPO, C.P., DINAPOLI, R.J. y HUNT, T.L. Commentary: Rain, Sun, Soil, and Sweat: A Consideration of Population Limits on Rapa Nui (Easter Island) before European Contact. Front. Ecol. Evol, 2018, vol. 25, n6. https://doi.org/10.3389/fevo.2018.00025 
LIPO, C. P., DINAPOLI, R.J., MADSEN, M.E. y HUNT, T.L. Solutions to Drift on Small and Isolated Populations: The Case of Rapa Nui (Easter Island, Chile). Paper presented at the $76^{\text {th }}$ Annual Meeting Society for American Archaeology. Albuquerque, 2019.

LIPO, C.P. y HUNT, T.L. AD 1680 and Rapa Nui Prehistory. Asian Perspectives, 2019, n 48, p. 309317.

LIPO, C.P., HUNT, T.L. y DINAPOLI, R.J. Temporal Systematics: The Colonization of Rapa Nui (Easter Island) and the Conceptualization of Time, en: NAPOLITANO, M., DINAPOLI, R.J. y STONE, J. (Eds.), The Archaeology of Island Colonization. Gainesville: University Press of Florida. Por publicar,

LIPO, C.P., HUNT, T.L., HORNEMAN, R. y BONHOMME, V. Weapons of Warfare? Rapa Nui Mata'a Morphometric Analyses. Antiquity, 2016, vol. 90, n³49, p. 172-187.

LIPO, C.P., HUNT, T.L. y HUNDTOFT, B.. Stylistic variability of stemmed obsidian tools (mata'a), frequency seriation, and the scale of social interaction on Rapa Nui (Easter Island). Journal of Archaeological Science, 2010, $n^{\circ} 37$, p. 2551-2561.

LIPO, C.P., HUNT, T.L. y RAPU HAOA, S. The 'Walking' Megalithic Statues (Moai) of Easter Island. Journal of Archaeological Science, 2013, n 40, p. 2859-2866.

LIPO, C.P., MISCHEN, P., y HUNT, T. L. Lessons from Rapa Nui (Easter Island, Chile) for governance in conditions of environmental uncertainty, en: GLÜCKLER, J. (Ed.), Knowledge for Governance. Suiza: Springer-Verlag. Por publicar.

MANN, D., EDWARDS, J., CHASE, J., BECK, W., REANIER, R., MASS, M., FINNEY, B. y LORET, J. Drought, vegetation change, and human history on Rapa Nui (Isla de Pascua, Easter Island). Quaternary Research, 2018, n69, p. 16-28.

MARTII I PUIG, S. The Emergence of Indigenous Movements in Latin America and Their Impact on the Latin American Political Scene: Interpretive Tools at the Local and Global Levels. Latin American Perspectives, 2010, vol. 37, n 6, p. 74-92. https://doi.org/10.1177/0094582X10382100

MISCHEN, P., HOMSY, G., LIPO, C., HOLAHAN, R., IMBRUCE, V., PAPE, A., y REINA, M. A Foundation for Measuring Community Sustainability. Sustainability, 2019, vol. 11, n 7, p. 1903. https://doi. org/10.3390/su11071903

MORRISON, A. An archaeological analysis of Rapa Nui settlement structure: A multi-scalar approach. Anthropology Ph.D, 2012.

MULROONEY, M.A.Continuity or Collapse? Diachronic Settlement and Land Use in Hanga Hoonu, Rapa Nui (Easter Island). Anthropology Ph.D, 2012. 
MULROONEY, M.A. An island-wide assessment of the chronology of settlement and land use on Rapa Nui (Easter Island) based on radiocarbon data. Journal of Archaeological Science 2013, $n^{\circ}$ 40, p. 4377-4399.

MULROONEY, M.A., LADEFOGED, T.N., STEVENSON, C.M., y HAOA, S. The Myth of AD 1680: New evidence from Hanga Ho'onu, Rapa Nui (Easter Island). Rapa Nui Journal, 2009, n²3, p. 94-105.

OSTROM, E. Governing the Commons: The Evolution of Institutions for Collective Action. Nueva York: Cambridge University Press, 1990.

PETERS, B.G. y PIERRE, J. Governance Without Government? Rethinking Public Administration. Journal of Public Administration Research and Theory, 1998, n 8, p. 223-243. https://doi. org/10.1093/oxfordjournals.jpart.a024379

PULESTON, C.O., LADEFOGED, T.N., HAOA, S., CHADWICK, O.A., VITOUSEK, P.M. y STEVENSON, C.M. Rain, sun, soil and sweat: A consideration of population limits on Rapa Nui (Easter Island) before European contact. Frontiers in Ecology and Evolution, 2017, n 5, p. 69.

RAMIREZ, J.M. Rapa Nui Land Management: A Personal Chronicle. Rapa Nui Journal, 2000, $n^{\circ} 14$, p. 47-48.

REYNOLDS, K y ROSE-PRICE, T. Rapa-Nui: The Easter Island legend on film. Nueva York: Newmarket, 1994.

SIMPSON, D.F., WEISLER, M.I., ST PIERRE, E.J., FENG, Y. y BOLHAR, R. The archaeological documentation and geochemistry of the Rua Tokitoki adze quarry and the Poike fine-grain basalt source on Rapa Nui (Easter Island). Archaeology in Oceania, 2018, vol. 53, n 1. https://doi.org/10.1002/ $\operatorname{arco.5132}$

SIMPSON JR., D.F. y DUSSUBIEUX, L. A collapsed narrative? Geochemistry and spatial distribution of basalt quarries and fine-grained artifacts reveal communal use of stone on Rapa Nui (Easter Island). Journal of Archaeological Science: Reports, 2018, n 18, p. 370-385. https://doi.org/10.1016/j.jasrep.2018.01.038

STEVENSON, C.M., PULESTON, C.O., VITOUSEK, P.M., CHADWICK, O.A., HAOA, S. y LADEFOGED, T.N. Variation in Rapa Nui (Easter Island) land use indicates production and population peaks prior to European contact. Proceedings of the National Academy of Sciences, 2015, n 112, p. 10251030.

STEVENSON, C.M., WOZNIAK, J. y HAOA, S. Prehistoric agricultural production on Easter Island (Rapa Nui), Chile. Antiquity, 1999, n 73, p. 801-812.

TECTOR, A. The delightful revolution: Canada's medical expedition to Easter Island, 1964-65. British Journal of Canadian Studies, 2014, n²7, p. 181-194. 
UNEP. Emerging issues for Small Island Developing States: Results of the UNEP Foresight Process. Nairobi: United Nations Environmental Programme (UNEP), 2014. Recuperado de: https://wedocs. unep.org/rest/bitstreams/16063/retriev.

UNITED NATIONS. World Economic Situation and Prospects 2014, 2014. Recuperado de: http:// unctad.org/en/PublicationsLibrary/wesp2014_en.pdf. United Nations.

VILLALBA, U. Buen Vivir vs Development: a paradigm shift in the Andes? Third World Quarterly, 2013, vol. 34, n 8, p. 1427-1442. https://doi.org/10.1080/01436597.2013.831594

WALSH, C. Development as Buen Vivir: Institutional arrangements and (de)colonial entanglements. Development, 2010, vol. 53, no 1, p. 15-21. https://doi.org/10.1057/dev.2009.93

WEISS, T.G. Governance, good governance and global governance: Conceptual and actual chaIlenges. Third World Quarterly, 2010, n²1, p. 795-814. https://doi.org/10.1080/713701075

WHITE, G. Indigenous Governance in Melanesia. Research School of Pacific and Asian Studies, Australian National University. Discussion Paper 2007/5. https://openresearch-repository.anu.edu. au/bitstream/1885/10105/1/White_IndigenousGovenance2007.pdf

WOZNIAK, J.A. Prehistoric horticultural practices on Easter Island: lithic mulched gardens and field systems. Rapa Nui Journal, 1999, n 13, p. 95-99. 
